\title{
How to Determine when a New Building Product is Suitable - Certifications and Experience
}

\author{
Ernst J. de Place Hansen ${ }^{1}$, Jørgen Nielsen ${ }^{1}$, Eva B. Møller ${ }^{2}$ and Ruut H. Peuhkuri ${ }^{1}$ \\ ${ }^{1}$ BUILD, Aalborg University, Campus Copenhagen, A.C. Meyers Vænge 15, 2450 Copenhagen SV, \\ Denmark, deplace@build.aau.dk,jn1@build.aau.dk, rup@build.aau.dk \\ ${ }^{2}$ Dept. of Civil Engineering, Technical University of Denmark, 2800 Kongens Lyngby, Denmark, \\ ebmo@byg.dtu.dk
}

\begin{abstract}
Previously, only solutions with long-term experience were used in the building sector and it was sufficient to describe, e.g. in the building regulations, how they should be constructed. However, the innovation rate has gradually increased, encouraged by industrialization and by building regulations becoming more functional based. As a result, the required performance is often described for the whole building or for a building component, but not at product level. Furthermore, CE marking makes it possible to market and sell a product in any country within the European Union if only one or a few properties are declared, and these may even not be the most relevant ones for a specific application in a technical solution. A CE mark is therefore neither a quality mark nor an approval of the product for a specific application, although clients and consultants often believe this is the case. It is therefore a major challenge for the building sector to determine if a new building product is suitable in a specific technical solution (wall, roof, etc.). The paper identifies a gap between performance-based requirements for a technical solution and specific requirements to properties of building products. Two cases (flat roofs with no slope, $\mathrm{MgO}$-containing boards used as wind barriers) show the possible economic consequences of not closing this gap; the technical solution failed, as one of the products was not suitable for Danish weather conditions. The first case initiated the formation of the Danish Building Defects Fund in 1986, the second one from 2015 shows that the gap still exits, 30 years later. The cases show how difficult it can be even for professionals to understand different certifications, especially when a product seems to be well suited for a specific use. Based on the cases, the paper presents a systematic approach that guides users through important issues relating to requirements for a moisture-safe building envelope.
\end{abstract}

Keywords: CE Marking, Building Products, Performance-Based Requirements, Documentation of Properties, Decision Chart.

\section{Introduction}

Previously, only solutions with long-term experience were used in the building sector and it was sufficient to describe how the solutions should be constructed; consequently the innovation rate was low. In Denmark, this was more or less the case until construction of buildings became gradually industrialized in the late 1950s and early 1960s, to accommodate the increased demand of dwellings after the Second World War. Industrialization is characterized by innovation and construction of a large number of buildings with almost the same technical solutions, reducing the construction time and/or the manpower. However, this means that a mistake can be reproduced many times before a lack of performance is discovered, and by then the economic consequences may be large. The innovation rate has gradually increased, 
encouraged by building regulations becoming more functional based. As a result, technical solutions used in building projects are often only described by the required performance.

The challenge of how to handle a high innovation rate has been recognized for many years, both nationally, e.g. (Blach \& Christensen, 1974) and internationally e.g. (CIB, 1982). Normally, the way to evaluate a new product is to compare it with an existing product with a known performance, although this presupposes that the properties of the existing product are relevant and sufficient. A technical solution (a wall, a roof, etc.) is normally composed by several products (bricks, insulating materials, membranes, wood panels, etc.), for which specifications may be available. The challenge is to close the gap between performance-based requirements (durability, thermal insulation, etc.) specified for a technical solution, and specific requirements to properties of products included in the solution. This is especially important when new or not fully tested products are introduced, or when well-known products are used in new combinations.

The cases presented in Section 2 illustrate how expensive it may be if the gap of documentation has not been closed. Therefore, the building sector needs guidance to evaluate if technical specifications of products lead to the fulfilment of performance-based requirements for a complete technical solution. A method for systematic review of products is described and discussed in Seetion 3 and 4.

\section{Expensive Experiences}

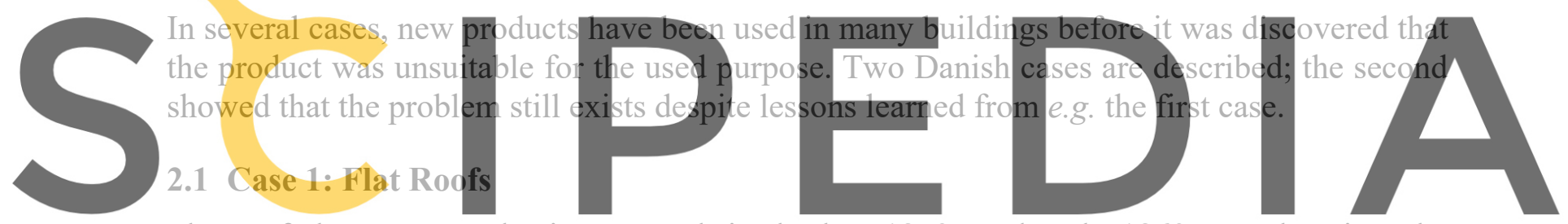

Flat roofs became popular in Denmark in the late 1950s and early 1960s. At that time the

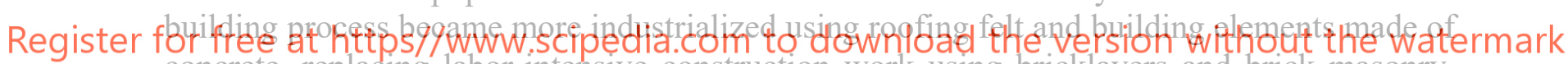
concrete, replacing labor-intensive construction work using bricklayers and brick masonry. Until 1972, the building regulations required that roofs had a slope towards drain, but in a tenyear period until 1981, when many large industrialized housing projects were constructed, there was no minimum requirement for roof slope. Unfortunately, complete flat roofs were difficult to execute with sufficient quality and the roofing materials were not durable for this solution. Therefore, many roofs leaked and resulted in expensive renovation projects and claims corresponding to $4 \%$ of the contract sum for dwellings with flat roofs (Bunch-Nielsen, 2019).

This experience and similar cases initiated the formation in 1986 of the Danish Building Defects Fund (www.bsf.dk), a mandatory insurance-based system for social housing projects, combined with a guidance on quality assurance in construction that counts for governmental and publicly subsidized building projects (National Building Agency, 1986). This was based on the expectation that preventing damage and defects is less expensive than doing repairs, for the society as a whole as well as for the building sector. Today, claims on flat roofs are down to $0.1-0.2 \%$ and the service life of this type of roof construction has increased from 10-15 years to 30-40 years (Bunch-Nielsen, 2019). 


\subsection{Case 2: Magnesium Oxide Containing Boards as Wind Barrier}

Around 2007, a new type of building boards was introduced in Denmark as an alternative to traditional products used as wind barrier on the cold side of the insulation layer in a lightweight facade construction. The boards were strong, fire resistant, light, cheap and good for the working environment. The boards were quickly taken up by the market as a new, interesting product. However, in 2015 it was realized that these new boards were not at all suited as wind barrier under normal Danish weather conditions.

The boards contain $\mathrm{MgO}$, which is a salt with a relatively low equilibrium moisture content, taking up moisture from the surrounding air when the relative humidity is high. Once saturated, the boards release salty liquid (Figure 1) that make screws, fittings and staples corrode and eventually initiate wood rot in surrounding wooden elements. In the longer run, the boards may disintegrate and lose their fire resisting, wind protecting and stabilizing properties. The Danish Building Defects Fund (2015a) declared promptly that they would not cover new claims related to building projects using $\mathrm{MgO}$ containing boards. They had by then been used in almost 20.000 social housing homes in Denmark and in an unknown number of single-family homes, private housing, schools, day care centers, hospitals, and industrial and commercial buildings. The cost of replacing boards alone in social housing dwellings has been estimated to around 1 billion DKK (Danish Building Defects Fund, 2015b).
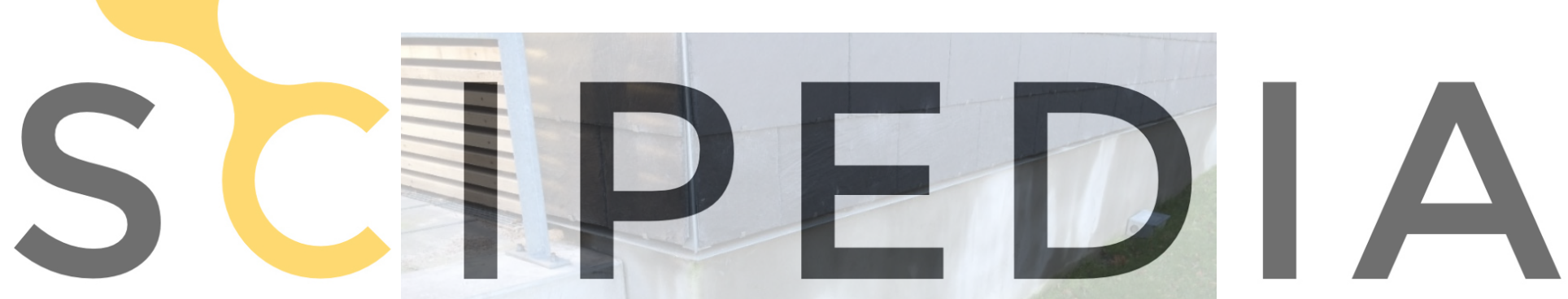

Register for free at https//www.scipedia.com to download the version without the watermark

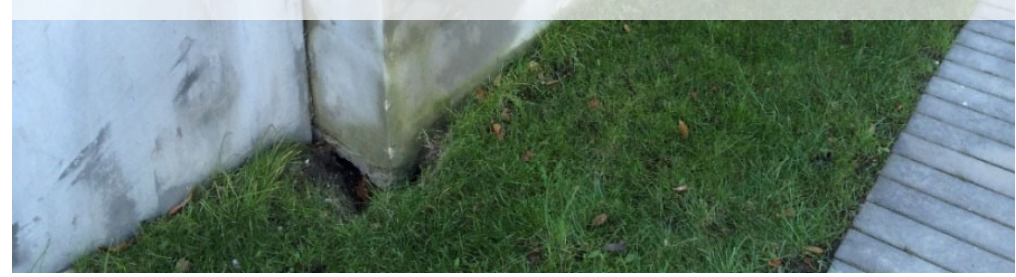

Figure 1. Wetting of a concrete foundation revealing that salty liquid has been released from $\mathrm{MgO}$ boards in the above lightweight external wall. Photo: Tommy Bunch-Nielsen.

A legal sequel is on-going; In one case, the architect/consultant was judged as being responsible for not having presented clearly enough to the client, that the product was not thoroughly tested. In another case, the contractor was acquitted as he had followed recommendation from BYG-ERFA published in 2013 (BYG-ERFA, 2013) stating that MgOcontaining boards were used as wind barriers, indicating that it had become a well-known product for this use. Since 2015, BYG-ERFA warns against this use of the boards (BYG-ERFA, 2015). 
The binder in $\mathrm{MgO}$ board is formed by a chemical reaction between $\mathrm{MgO}$ and $\mathrm{MgCl}_{2}$. Boards containing $\mathrm{MgSO}_{4}$ were later introduced to the market because of the less hygroscopic behavior of $\mathrm{MgSO}_{4}$ compared to $\mathrm{MgCl}_{2}$ but they showed not to be a feasible alternative in Denmark and countries with a similar humid climate (Wøhler Nielsen et al., 2019).

\section{Systematic Review of New Products}

To reduce the risk of using unsuitable products in technical solutions, decision makers need a way to review products. A method for a systematic review presented in this section is based on (Peuhkuri, Nielsen, and Møller, 2020) and (BYG-ERFA, 2017). It is a guideline to buyers of building products and other partners in a building project, who are supposed to demand documentation of relevant properties for new products or products used in a new way. Determination of requirements for products used in lightweight external walls is used as an example. The client should expect the consulting architect/engineer to:
Identify new solutions in the building design
Make sure that all relevant requirements for documentation of each product in each new solution is detailed and highlighted in the project documents (further detailed below) Ensure that suppliers' information about the product and documentation for critical parameters is present and critically evaluated.

Function of a product in a given solution. The function of a product must be identified before

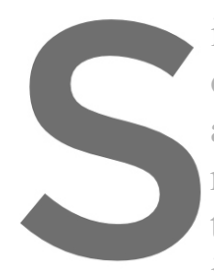
it is possible to identify the relevant properties. Opposed to a s
of a lightweight exterior wall often are highly divided betwe
acts as a vapor barrier, another as load bearing structure, etc.
new solutions where one product can be replaced by another di
that the wall has to fulfil, provided that the products do not ha is a general requirement for durability. Further, not only the

Further, notonly the performance of the wall itself but

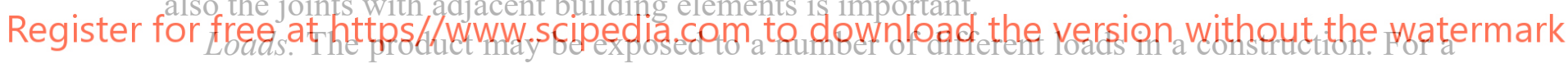

lightweight exterior wall, the position of the product in the wall determines the degree of the moisture load. Every load, including fire, freezing point passages, UV-exposure etc., must be quantified if relevant, including loads during the construction phase.

Relevant properties. The intended function of a specific product as part of a planned solution (e.g. that it contributes to the thermal insulation) and the loads it will be exposed to in the actual position in the solution, including loads during the construction phase, must be defined. This forms the basis for deciding which technical properties the product must be in possession of to function as expected in the solution.

Specification of requirements. A list of the specific requirements for a product to be used as intended in the technical solution can be based on a relevant harmonized European standard or a European Technical Assessment (ETA) in case the product is not covered by a standard. However, standards covering specific types of products, e.g. plasterboard or insulation, normally relate to product properties only and not to properties related to the technical solution, e.g. strength, fire resistance and sound insulation. In case a standard covers a technical solution, for example a lightweight wall, it usually focuses on statics and fire safety issues. 
This means that where moisture loads are important, it is necessary (and legal) to supplement with requirements for moisture related properties, assuming these properties cannot be declared based on harmonized standards. This may be requirements related to moisture content at a specified relative humidity in the surrounding air, free water uptake, drying rate after water uptake, mechanical and chemical stability associated with moisture absorption, and durability in relation to moisture content. In addition, requirements for buildability must be included. In case it is decided to replace a product by another, the alternative product have to meet all the requirements, and not only one of them.

Documentation of product properties. For each of the listed requirements reference to a test standard shall be made. If a relevant harmonized European standard exists, it must be used.

\section{Discussion}

The cases in Section 2 illustrates, as previously stated in (de Place Hansen, 2013), that the buildings regulations' increasing use of performance-based requirements highlights the need for recommendations for levels of requirements for technical solutions and for communication about the experience with building products and solutions. Further, that building professionals should reflect more on the feasibility of a product or solution in a specific context, without having 40 years of experience from practice, as a lack of service life data not necessarily prevents new products and solutions to be promoted (de Place Hansen and Møller, 2015).

The introduction of CE marking makes it possible to market and sell a specific product in

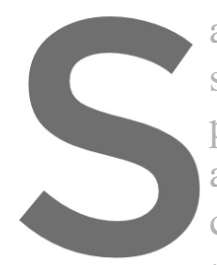
any country within the Europdan Union (EU). However, a CE
specific properties of a building product. does not guarantee t
performance-based building requirements, being national based.
a quality mark nor an approval of the product for a specific ap
consultants often believe this is the case. A proctuct can get a minimum requirement for a single property,
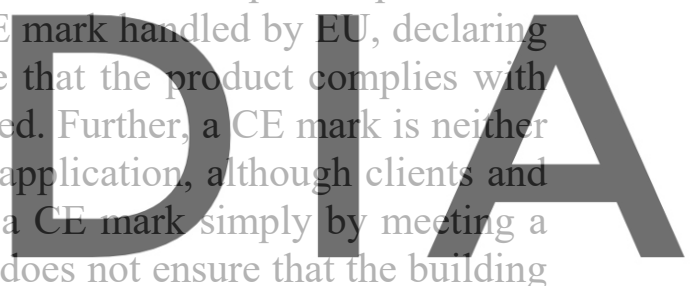
product has all the relevant properties.

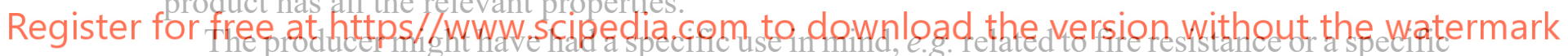

climate, and not that it would be used in a climate where moisture related properties would be more relevant to document, but national authorities cannot force remaining properties to be declared. Further, a new product or a new use of a product is often not covered by a harmonized standard and an ETA is not necessarily issued, i.e. a CE mark is not required. It is therefore a major challenge for the building sector to determine if a new product is suitable in a specific technical solution, e.g. being able to withstand hygrothermal load during 40 years of use in a building envelope. Experience from the Danish Building Defects Fund has shown that requirements in relation to moisture are not sufficiently well formulated.

Further, by combining existing products with new products in a technical solution, it is necessary to expose how both new and existing products behave, to estimate how the combination will react, although this is not always sufficient (Ingeniøren, 2019). In general, the more products that are part of a technical solution, the harder it is to formulate product specifications for a solution adequate for a specific geographical location.

To close the gap between performance-based requirements and product specifications in an economical way, a simple, straightforward decision chart is suggested (Figure 2), combining the information presented in Section 3. 


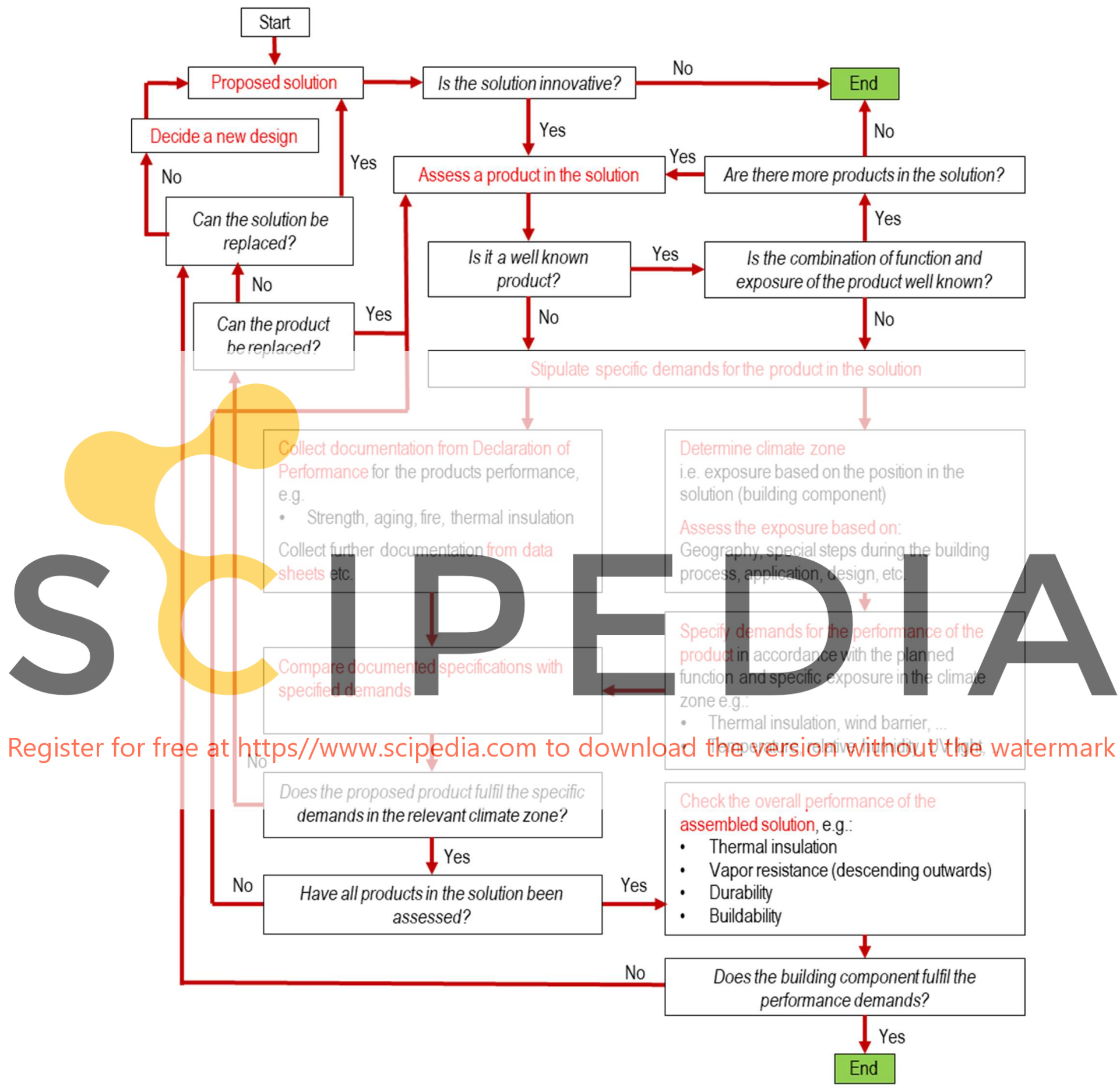

Figure 2. Decision chart guiding the user to ensure a suitable solution for an external lightweight wall, focusing on moisture related properties. Green boxes: A usable solution has been reached. Text in italic: Questions to be answered by the user. Boxes with text in red: Actions to be taken by the user. A guideline and eventually a checklist should expand each of these boxes. 
The decision chart forces the user to consider different function-based requirements and guides the user through the most important issues to ensure a suitable solution for the building envelope, using a lightweight wall as an example. To use the chart for other types of external walls or other building elements, guidelines/checklists detailing the content of boxes with text in red should focus more on issues relating to statics, fire resistance, etc. The chart clarifies whether the risks the client takes are reasonable compared with the economic benefits. It can be used for both well-proven solutions with many years of good experience, as for new, innovative products or solutions. The more new products a technical solution includes, the harder the work to make it to the end of the decision chart.

The consultant must decide which requirements are needed for products used at a specific position in a specific technical solution for a building component. A documentation of this could be a part of a statement/declaration on risky conditions, including a description of how to minimize the risk. Together with an evaluation of the costs, the client has now a basis to decide whether he will accept the suggested innovative solution. For products used as roofing underlay this work has already been done in Denmark with the introduction of DUKO in 2004, an independent company that classifies roofing underlays and (since 2013) vapor barrier systems (https://duko.dk). Although this is a voluntary scheme, within a few years DUKO has increased the quality of roofs and reduced the amount of defects (Møller and Hansen, 2017).

In other wall types or in technical solutions used in other parts of the building envelope, the products involved may not have as specific functions as in lightweight walls. Nonetheless, it is still relevant to follow a systematic approach to ensure that all the relevant considerations are
made when evaluating whether a strggested solution is stitable. As an example, a wall element
that functions both as a load bearing structure, as thermal insulation and as a vapor barrie of
course has to document all the properties relevant to comply with these functions when used at
a specific geographical location.
For each new product, it can be costly to canty out tests to document whether it fulfils specific made when evaluating that functions both as course has to document a specific geographical For each new product requirements, especially if the product can be used in many combinations with other products.

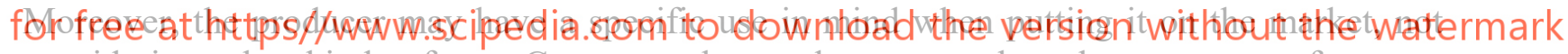
considering other kinds of use. Consequently, producers may be reluctant to test for more properties than necessary for the intended use. Likewise, consultants and contractors neither have the time nor money to organize testing for more properties.

\section{Conclusion}

A gap between performance-based requirements specified for a technical solution and specific requirements to properties of products has been identified. Cases show that this gap still exists (second case) although problems with identification of relevant product requirements has been known for at least 30 years (first case). Further, cases show that it can be very expensive to use new products or technical solutions in a specific context if not all relevant properties are documented or if the products are not used as intended.

Closing the gap simply by asking for more documentation is not trivial as testing is expensive, and often the consultant lacks knowledge to identify what is relevant without a systematic approach. A decision chart was developed to guide the consultant into the needed systematic approach when deciding whether a specific product or solution is acceptable. 


\section{Acknowledgements}

The development of the proposal for a systematic review of products and the decision chart presented in Section 3 and 4 was made possible by a grant from the Danish Building Defects Fund.

\section{ORCID}

Ernst J. de Place Hansen: https://orcid.org/0000-0002-6906-3793

Jørgen Nielsen: http://orcid.org/0000-0001-8065-4036

Eva B. Møller: http://orcid.org/0000-0001-8404-0859

Ruut H. Peuhkuri: https://orcid.org/0000-0001-7682-8515

\section{References}

Blach, K. and Christensen, C. (1974). Ydeevne - hvorfor, hvordan? (In Danish; author's translation: Performance - why, how?). Danish Building Research Institute, Copenhagen.

Bunch-Nielsen, T. (2019). Written communication.

BYG-ERFA (2013). Vindspcerrer i facader - materialevalg og afdcekning i byggeperioden (In Danish; author's translation: Wind barriers in facades - choice of material and covering in the building period) (BYG-ERFA Experience sheet (21) 1312 27). Copenhagen.

BYG-ERFA (2015). Fugtsugende vindspcerreplader (In Danish; author's translation: Moisture absorbing wind barrier boards (BYG-ERFA Experience sheet (21) 1505 05). Copenhagen.

BYG-ERFA (2017). Byggevarer og CE moerkning (In Danish; author's translation: Building products and CE marking) (BYG-ERFA Experience sheet (99) 1706 05). Copenhagen.

CIB (1982). Working with the performance approach (CIB Report, Publication 64). Working Commission W060, CIB, Rotterdam, The Netherlands. http://www.irbnet.de/daten/iconda/CIB_DC23969.pdf

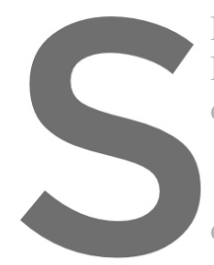

Danish Building Defects Fun

Danish Building Defects Fun

de Place Hansen, E.J. (2013)

Proc. 19th CIB World

2013). (S. Kajewski, K

de Place Hansen, E.J. and M
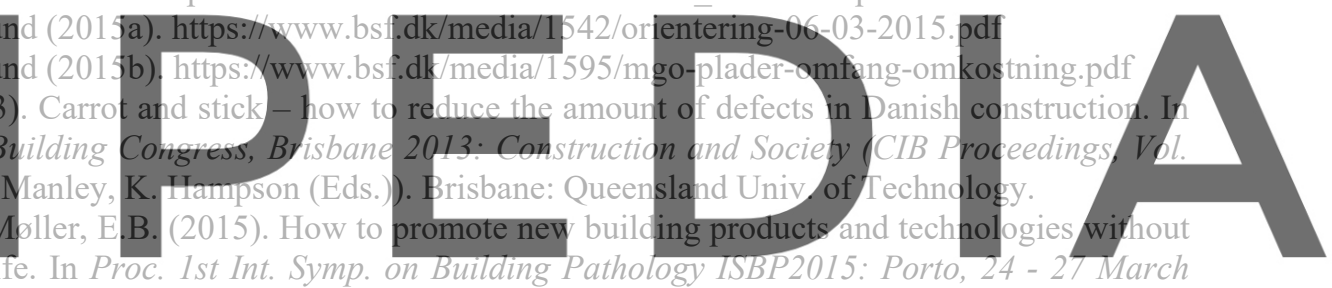

knowing their service 1ife. In Proc. Ist Int. Symp. On Bulling Pathology ISBP2015: Porto, 4 - 27 March 2015. Peixoto de Freitas, V., de Angelis, E., Corvacho, H., Delgado, J. M. P. Q. \& Guimarães, A. S. (red.).

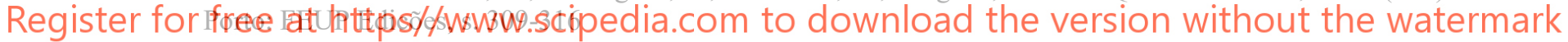

Ingeniøren (2019). Bekymrende overraskelse: Ufarlige byggematerialer bliver til en giftig cocktail. (In Danish; author's translation: Disturbing surprise: Harmless building materials become a toxic cocktail). Ingeniøren, 21 Oct 2019. Copenhagen. https://ing.dk

Møller, E.B. and Hansen, T. (2017). Artificial aging of air and vapour barriers. In Proc. 14th International Conference on Durability of Building Materials and Components (XIV DBMC), 29-31 May 2017, Ghent University, Ghent, Belgium, 285, 1-12.

National Building Agency (1986). Vejledning om kvalitetssikring i byggeriet (In Danish; author's translation: Guidance on quality assurance in construction) (VEJ nr. 4024 af 31/12/1986). Copenhagen

Peuhkuri, R., Nielsen, J. and Møller, E.B. (2020). Specifikation af krav til bygningsdele i klimaskcermen (In Danish; author's translation: Specification of requirements for solutions in the building envelope) (SBi 2020:11). Department of the Built Environment, Aalborg University, Copenhagen.

Wøhler Nielsen, S., Rode, C., Bunch-Nielsen, T., Kielsgaard Hansen, K., Kunther, W. and Grelk, B. (2019). Properties of magnesium oxide boards used as sheathing in exterior walls. $4^{\text {th }}$ Central European Symposium on Building Physics (CESBP), Prague, 2-5 Sep 2019, MATEC Web of Conferences vol. 282, 02091. https://doi.org/10.1051/matecconf /201928202091 